\title{
Aproveitamento de rejeitos da cadeia hortofrutícula no processamento de plásticos biodegradáveis
}

\author{
RESUMO
}

\section{Taís Téo de Barros}

tais.teo@hotmail.com.br
Universidade Federal de São Carlos Universidade Federal de São

Milena Martelli Tosi

mmartelli@usp.br

Universidade de São Paulo (USP),

Pirassununga, SP, Brasi

Odílio Benedito Garrido Assis odilio.assis@embrapa.br

Embrapa Instrumentação (CNPDIA), São Carlos, SP, Brasil
O presente texto apresenta e comenta, de maneira simplificada, um processo básico de produção de plásticos biodegradáveis, de interesse à indústria de embalagens, utilizando como matéria-prima rejeitos ou descartes da cadeia hortofrutícula. O objetivo aqui é o de despertar interesse do setor industrial em estudos de viabilidade econômica do processo proposto. O Brasil embora seja um dos maiores produtores de frutas e hortaliças do mundo, também está entre os países que somam as maiores perdas neste segmento. Frutas e hortaliças sobremaduras, inadequadas ao consumo, ou rejeitos da agroindústria são materiais subutilizados ou mesmo descartados, mas se processados adequadamente podem constituir em matéria-prima de interesse na produção de filmes plásticos comestíveis e biodegradáveis. As perdas ou resíduos somam em torno de $40 \%$ de toda a produção de frutas o que significa uma farta fonte de matéria-prima a baixo custo que pode ser aproveitada pelas indústrias no processamento de plásticos, não só para o aumento da carteira de produtos, mas também para agregar valor à imagem de sustentabilidade. A confecção de filmes a partir de polpa de mamão é apresentada como exemplo ilustrativo da viabilidade do processo.

PALAVRAS-CHAVE: Embalagens. Plásticos Biodegradáveis. Rejeitos Agroindustriais, Processamento Sustentável. 


\section{INTRODUÇÃO}

Estima-se que em 2016 a produção mundial de frutas frescas atingiu montantes superiores a 640 milhões de toneladas, sendo o Brasil responsável por aproximadamente $7 \%$ desse valor, ou seja, 44 milhões de toneladas de frutas colhidas de aproximadamente 500 diferentes variedades (SABIO et al., 2016). Esta produção é bastante significativa e posiciona o Brasil como o terceiro maior produtor mundial ficando atrás apenas da China e da Índia, que colhem 190 e 86 milhões de toneladas respectivamente (SEAB, 2012).

Segundo dados disponibilizados pelo Instituto Brasileiro de Geografia e Estatística - IBGE, a fruticultura brasileira representa 11,5\% do PIB agrícola e $0,62 \%$ do PIB nacional (IBGE, 2015). Embora seja um grande produtor, o mercado hortifrutícola brasileiro ainda é caracterizado por ser eminentemente interno. Do montante produzido apenas $31 \%$ é exportado (seja na forma de frutas frescas ou processadas), e o restante, aproximadamente 30 milhões de toneladas, destinado ao consumo interno (BRAZILIAN FRUIT, 2016).

Contudo estima-se que em torno de 30 a $40 \%$ das frutas destinadas ao mercado interno sejam descartadas por motivos diversos. Pode-se citar a colheita de frutos imaturos associados à ausência de boas práticas e de logística adequada como manuseio irregular, inexistência da cadeia de frio, infraestrutura precária de acondicionamentos, transporte e distribuição como os maiores vilões dessas perdas (SANTOS; VIERA, 2011).

Mesmo para aqueles produtos destinados ao processamento mínimo (corte, descasque e retirada de sementes), temos a geração de 30 a $70 \%$ de resíduos (MORETTI, 2006). No processamento de sucos, nos quais predominam os citros, a geração de subprodutos (cascas, bagaços ou polpas) corresponde a aproximadamente 30 a $40 \%$ da massa total da fruta (NASCIMENTO-FILHO; FRANCO, 2015).

Configura-se assim um cenário em que há uma grande geração de resíduos orgânicos, com um aproveitamento ínfimo (atualmente a principal reutilização ou processamento desses resíduos destina-se a produção de ração animal, com utilização inferior a 10\% do total de material disponível (CRUZ et al., 2013)). Desta forma tornou-se prática usual o descarte desses resíduos in natura sem nenhum tratamento ou controle o que, embora de origem orgânica, podem causar graves impactos ambientais.

Diversos estudos têm sido empenhados na valoração de resíduos e efluentes de origem agroindustrial, como reutilização como substratos para a geração de biomassa microbiana (SILVA, 2001), na extração de compostos bioativos de interesse alimentícios ou farmacêuticos (SANTANA-MÉRIDAS; GONZÁLEZCOLOMA; SÁNCHEZ-VIOQUE, 2012), em processos de produção de fertilizantes por reações induzidas ou por compostagem (ROSA et al., 2011), na produção de fibras para emprego como elemento de reforço para matrizes poliméricas (MARTELLI-TOSI et al., 2017) ou em materiais de uso na construção civil (EHRENBRING \& TUTIKIAN, 2016) e na produção de substratos reativos destinados à produção de biocombustíveis (SOUZA et al., 2012), entre outras possibilidades.

Uma alternativa relativamente simples e viável para o aproveitamento de resíduos da cadeia hortofrutícula é o emprego desses descartes no 
processamento de filmes biodegradáveis. A tecnologia para este processamento teve seu inicio de desenvolvimento nos EUA a partir dos trabalhos realizados junto ao Departamento de Agricultura Americano, ARS-USDA, coordenados por McHUGH; HUXSOLL \& KROCHTA, em 1996, através do processamento de membranas elaboradas a partir da polpa de maçãs descartadas após o processamento de sucos. Essa produção de filmes a partir de resíduos hortofrutícola consistiu em um processo inovador e ainda pouco conhecido ou explorado em escala mundial. A Embrapa (Empresa Brasileira de Pesquisa Agropecuária) através de intercâmbio com o ARS-USDA introduziu recentemente este processo como linha de pesquisa em sua unidade de Instrumentação na cidade de São Carlos, SP, com foco no aproveitamento de rejeitos de frutas sobremaduras tropicais, principalmente aquelas de elevada perecibilidade, que quando inapropriadas ao consumo possam servir de matéria prima na confecção de filmes delgados de interesse à indústria de embalagens (SILVEIRA, 2016).

Os filmes obtidos a partir de polpas (ou purês) apresentam diversas características que se adequam à indústria de embalagens, como boa barreira ao oxigênio, particularmente em baixa ou moderada umidade, e propriedades mecânicas aceitáveis para o acondicionamento e transporte de pequenos volumes. Os plásticos processados a partir de polpas não têm como objetivo substituir os polímeros sintéticos convencionais, mas sim são sugeridos como uma alternativa à produção de embalagens de uso rápido no transporte doméstico e de descarte imediato. Adicionalmente, atributos sensoriais como cor, sabor e aroma podem ser preservados, ou mesmo enaltecidos, para emprego em certas aplicações como atrativos adicionais comparados aos demais filmes convencionais, inodoros e incolores.

\section{O EMPREGO DE PLÁSTICO COMO EMBALAGEM}

Atualmente os polímeros derivados de petróleo dominam as aplicações de plásticos para uso em embalagens. $O$ baixo custo de produção associado à versatilidade e à resistência desses materiais e a ausência de alternativas economicamente viáveis, fazem dos plásticos sintéticos materiais de difícil substituição.

A produção brasileira de plásticos gira em aproximadamente 65 milhões de toneladas ao ano, sendo que a metade deste montante é destinada à confecção de embalagens nas suas mais diversas formas (ABLIPAST, 2014). Embora vidros, madeiras, metais e cartonados sejam também empregados como material para a confecção de embalagens, o plástico é o que tem apresentado no último decênio o maior crescimento proporcional de produção e de emprego como embalagem (EMBANEWS, 2016).

Segundo levantamento realizado pela Associação Brasileira de Indústria de Embalagens Plásticas Flexíveis (ABIEF), em 2015 havia aproximadamente 12 mil empresas no país produzindo plásticos para embalagens, empregando mais de 300 mil profissionais diretos e com faturamento na ordem de $\mathrm{R} \$ 60$ bilhões anuais ( $\mathrm{DCl}, 2016)$. De um modo geral, o mercado total de embalagens no Brasil é bastante diversificado e movimenta o equivalente a US\$ 35 bilhões, o que representa aproximadamente 1,5\% do valor do PIB nacional (EMBANEWS, 2016). 
Temos assim uma indústria e um mercado consolidado no setor e com perspectivas de crescimento anual de $9 \%$, o que torna este um lucrativo segmento e aberto a inovações tecnológicas. Cabe ressaltar que diversas propostas no sentido de substituição dos plásticos tradicionais por similares biodegradáveis tramitam nos diversos níveis governamentais, podendo ser citado o Projeto de Lei número 612-A, de autoria do então deputado Flávio Bezerra, que advoga sobre a possibilidade de substituição total, em todo território nacional, das sacolas plásticas de uso em estabelecimentos comerciais por materiais biodegradáveis.

Neste contexto, o desenvolvimento de materiais alternativos destinados ao uso em embalagens biodegradáveis e de baixo custo, ainda que com características inferiores aos plásticos sintéticos podem, mesmo se empregados em menor escala, ajustar-se à legislação, agregar valores e trazer benefícios ambientais para uma série de cadeias produtivas.

\section{PROCESSAMENTO DE FILMES A PARTIR DE POLPLA OU PURÊ DE FRUTAS}

Os plásticos sintéticos (derivados de petróleo) são produzidos pela reação de condensação (polimerização) entre monômeros de hidrocarbonetos, com o auxílio de catalisadores químicos altamente reativos, gerando longas cadeias ramificadas e de alta massa molecular. Esses materiais são caracterizados por apresentarem facilidade de conformação (alta plasticidade), resistência à tração e baixa permeabilidade à água e vapores diversos, embora sejam ambientalmente agressivos por apresentarem baixa ou nenhuma biodegradabilidade.

Diferente dos sintéticos, o processamento básico de filmes a partir de popas é, em princípio, relativamente mais simples e dispensa o emprego de aditivos ou catalizadores. A matéria prima pode ser oriunda de qualquer fruta ou hortaliça na condição sobremadura ou do rejeito de seu processamento industrial. A elaboração da polpa segue processos usuais da área, similares aos descritos por DITCHFIELD \& TADINI (2005), com adaptações para cada polpa. Os filmes processados têm boa maleabilidade e apresentam razoável resistência mecânica, embora tenham uma elevada taxa de absorção de água.

Como exemplo descrevemos a seguir o preparo de uma polpa de mamão (Carica papaya L.) na condição sobremadura que é, de uma forma geral, muito próximo a sequência de preparação de purês de qualquer outra fruta ou hortaliça. Inicialmente os mamões, aqui foram empregados mamões da cultivar Formosa, foram higienizados (imersos em solução de cloro $200 \mathrm{mg}$ L-1 por 5 minutos, lavados em água corrente e secos na temperatura ambiente) e as cascas, regiões com indícios de apodrecimento e sementes removidas e descartadas. A polpa foi obtida por redução mecânica por liquefação/maceração por um período de aproximadamente 5 minutos, fazendo uso de um mixer ou liquidificador industrial. A cada $750 \mathrm{~g}$ de polpa, adicionou-se $250 \mathrm{~g}$ de água e 0,2 $\%(\mathrm{~m} / \mathrm{m})$ de ácido ascórbico e cítrico com o objetivo de inativar parcialmente as enzimas, principalmente a peroxidase (POD) e polifenol oxidase (PPO). Essas enzimas estão diretamente associadas ao escurecimento das frutas e sua interação com ácidos evita a oxidação dos substratos orgânicos preservando a coloração inicial da polpa. 
A mistura é então centrifugada por 5 minutos a uma rotação de $12.000 \mathrm{rpm}$ e o sobrenadante (parte não solúvel) removido. Na sequência, a polpa foi autoclavado a uma temperatura de 115 ㄷ C por 1 minuto, embalada a vácuo e preservada em refrigeração a $-20 \stackrel{\circ}{ } \mathrm{C}$ até seu uso. Este é o procedimento básico de processamento de polpa de frutas e o esquema da Figura 1 apresenta de forma ilustrativa esta sequência. $O$ rendimento de produção de polpa com relação a massa total utilizada é de 60 a $70 \%$ dependendo do tipo de fruta empregada.

Figura 1 - Esquema ilustrativo da preparação de polpa de fruta sobremadura, tendo o mamão (Carica papaya L.) como exemplo, segundo a sequência adotada pela Embrapa (imagens da Embrapa Instrumentação)

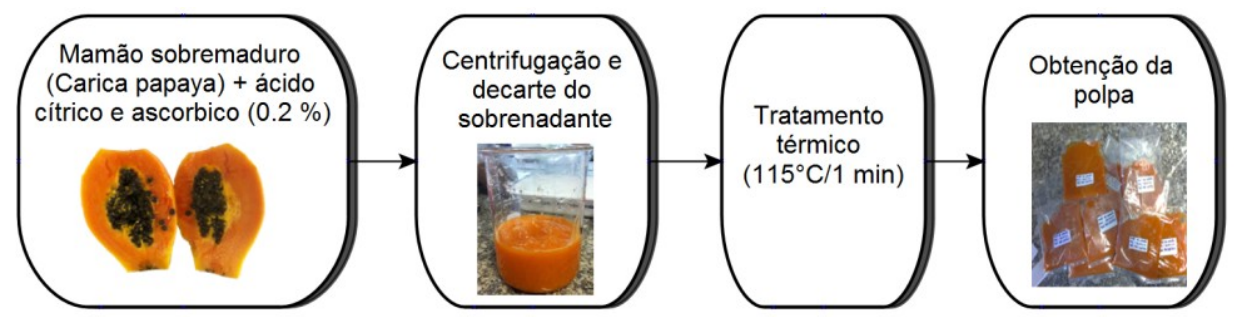

Fonte: Elaboração própria (2016).

$\mathrm{Na}$ unidade da Embrapa Instrumentação temos avaliado diversas concentrações relativas de massa seca (quantidade de purê por fração de solvente) no processamento dos filmes (DE BARROS, 2016) e porcentagens entre $20 \%$ a $25 \%$ têm se mostrado adequadas com respeito a obtenção de filmes com propriedades mecânicas e de permeação aceitáveis. A proporção de massa de polpa por água, como diluente, tem forte influência na espessura e secagem dos filmes, como será melhor detalhado ao longo deste texto. A adição de plastificantes de grau alimentício como glicerol, sorbitol e/ou pectina e em alguns casos (polpas muito fibrosas) é necessária. Normalmente a incorporação é realizada em pequenas frações (não superiores a 15\% com respeito à massa seca) para conferir uma maior plasticidade aos materiais permitindo assim o processamento de filmes com uma melhor maneabilidade.

Os filmes podem ser produzidos em batelada, tendo como processo básico o "casting", no qual a polpa é vertida sobre superfície plana apolar e após a "cura" ou polimerização as lâminas são removidas manualmente ou por laminação contínua, na qual a formulação é submetida a diversos rolos com espaçamentos previamente definidos e posterior remoção por destacamento contínuo. Um dos recursos fundamentais para o processamento de filmes com características homogêneas (superficiais e internas), e com propriedades mecânicas aceitáveis, é o uso de sistemas de processamento contínuo, como o Loabcoater Unit, produzida pela Werner Mathis de origem suíça, mas disponível para comercialização no Brasil (www.mathis.com.br), popularmente conhecida como Máquina Mathis. Esta "máquina" consiste em um equipamento modular que oferece uma grande quantidade de variações de montagem e de obtenção de parâmetros experimentais, sejam térmicos ou mecânicos (MARTELLI; DE BARROS; ASSIS, 2015). 
O sistema permite o processamento em batelada tendo como princípio a técnica de casting, para volumes definidos de polpa e redução de espessura por laminação individual em rolo compressor ou por processamento no modo de laminação contínua, no qual é possível a produção de filmes contínuos pela alimentação de maiores volumes de polpa sobre uma superfície apolar rolante (esteira) como suporte (normalmente filme comercial de polietileno de alta densidade). No modo laminação contínua, a carga depositada é conduzida em velocidade controlada e submetida a uma série de rolos laminadores em espaçamentos previamente definidos (módulo 1 ), sendo a polpa reduzida para a espessura desejada e conduzida a um sistema sequencial de fornos (2 câmaras) com temperaturas previamente ajustadas e com emissões e radiações (ultravioleta quando necessário para polimerização e/ou para a eliminação de microrganismos sensíveis) (módulos 2 e 3 ). O processamento no modo contínuo está esquematizado na Figura 2.

Figura 2 - Disposição modular do sistema contínuo Mathis, conforme montagem atual em operação na Embrapa: Módulo [?: 1 = rolo de suporte do filme de polietileno; 2 = posição de alimentação da polpa (realizada manualmente); 3 = sistema de facas redutoras do volume a ser laminado; 4 = rolos primários de laminação. Módulo [?: $5=$ sistema térmicos e de circulação de gases; 6 = alternativa para coleta do filme; $7=$ rolos secundários de laminação. Módulo [?: 8 = sistema térmicos com circulação de gases e emissão de radiação; 9 e 10 = suportes para a separação final do filme

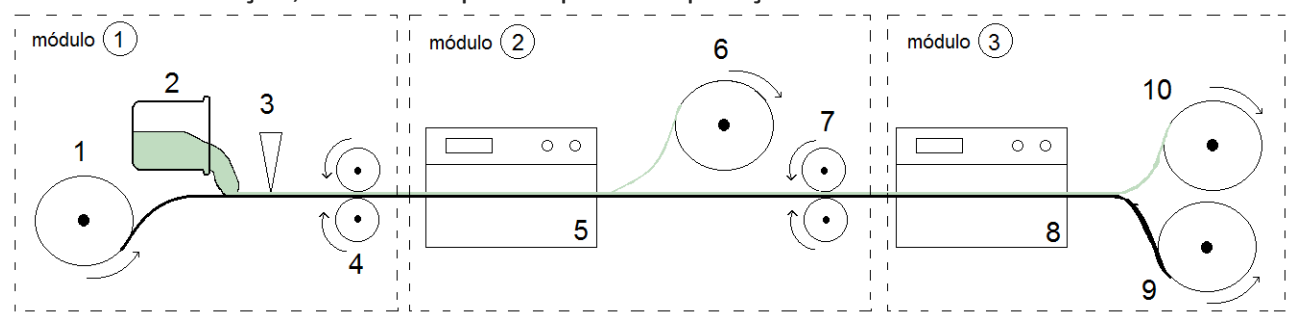

Fonte: Elaboração própria (2016).

De forma esquemática temos na Figura 2 a alimentação manual da carga (polpa) (2) sobre o suporte flexível (esteira) de polietileno (1). O posicionamento das facas (3) e rolos compressores sequenciais (4) e (7) que limitam o volume de material depositado podem ser fixados em posições estratégicas ao longo do deslocamento do suporte. As câmaras de aquecimento e cura (5) e (8) podem ter a temperatura, velocidade e entrada ou exaustão de gases controlados. $\mathrm{Na}$ câmera (8) pode ser programada a emissão contínua ou intermitente de radiação ultravioleta. O filme curado pode ser recolhido após um único ciclo térmico em (6) ou após um segundo aquecimento ou controle de espessura em (10). Detalhes com imagens e vídeos do sistema em operação estão disponibilizados no site do representante nacional em http://www.mathis.com.br/pt/produtos/revestimento_coating/8-filme. A título de ilustração, a Figura 3 apresenta o aspecto final de filmes de mamão, obtidas em lâminas por batelada na Embrapa. 
Figura 3 - Polpa de mamão depositada em sistema Mathis modo batelada e aspecto dos filmes gerados (imagens da Embrapa Instrumentação)

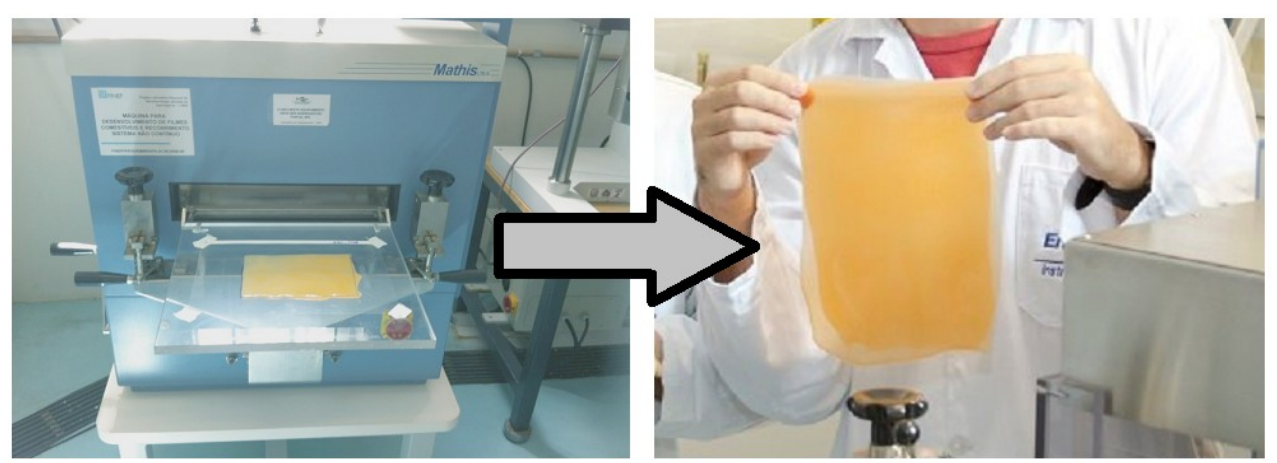

Fonte: Elaboração própria (2016).

É usual no processamento de filmes de polpa a formação de compósitos pela incorporação na matriz de elementos de reforços como fibras (AZEREDO et al., 2009) ou partículas (LOREVICE; MOURA; MATTOSO, 2014). A adição desses reforços tem considerável efeito na melhoria das propriedades mecânicas e na redução da permeação ao vapor de água, através do estabelecimento de ligações cruzadas entre as cadeias poliméricas, com resposta positiva também com respeito à redução de degradações pelo aquecimento (maior estabilidade térmica) (DE BARROS, 2016). A caracterização físico-química de filmes (com e sem elementos de reforços) e detalhes operacionais de todas as etapas do processo (nos modos batelada e contínuo) podem ser encontradas em MARTELLI; DE BARROS; ASSIS, (2015) e DE BARROS, (2016).

A título de comparação, a Tabela 1 agrupa resultados das propriedades mecânicas e de permeação de alguns filmes à base de polpa, conforme dados gerados em nossos trabalhos e demais obtidos na literatura.

Tabela 1 - Propriedades mecânicas (tensão máxima na ruptura: omax; deformação máxima: emax; módulo de elasticidade ou módulo de Young: (E) e de barreira (permeabilidade ao vapor d'água - WVP), para alguns filmes processados à base de polpa, conforme dados encontrados na literatura.

\begin{tabular}{lccccc}
\hline $\begin{array}{l}\text { Polpa } \\
\text { (filme) }\end{array}$ & $\sigma_{\max }(\mathrm{MPa})$ & $\varepsilon_{\max }(\%)$ & $E(\mathrm{MPa})$ & $\begin{array}{c}\text { WVP } \\
\left.\text { (g.mm/kPa.h.m }{ }^{2}\right)\end{array}$ & Referência \\
\hline \hline Mamão & 5,15 & 10,97 & - & 0,78 & DE BARROS, 2016 \\
\hline Tomate & 11,4 & 11,2 & 248 & 2,40 & DU et al., 2008 \\
\hline Cenoura & $7,5-21,9$ & $4,4-46,2$ & - & $0,26-0,99$ & WANG et al., 2011 \\
\hline Manga & 4,1 & 44,1 & 19,9 & 2,70 & AZEREDO et al., 2009 \\
\hline
\end{tabular}




\begin{tabular}{lccccc}
\hline Banana & 3,2 & 23 & 21 & 3,95 & MARTELLI et al., 2013 \\
\hline Maçã & 2,9 & 51,1 & 7,1 & 4,95 & $\begin{array}{c}\text { ROJAS-GRAÜ et al., } \\
2007\end{array}$ \\
\hline Goiaba & 5,4 & 2,2 & - & 2,09 & LOREVICE et al., 2012 \\
\hline Acerola & 0,77 & 23,11 & - & 0,20 & FARIAS et al., 2012 \\
\hline \hline
\end{tabular}

Fonte: Elaboração própria (2016).

Embora como já comentado esses valores sejam, evidentemente, inferiores aos obtidos em ensaios para os plásticos sintéticos, os filmes processados a partir de polpa de frutas apresentam homogeneidade de espessura e estabilidade estrutural além de boa manuseabilidade e conformação. São contudo, facilmente degradáveis em ambiente com alta umidade ou ao contato direto com água, sendo assim indicados para aplicações em embalagens de uso rápido.

Dentre os estudos realizados com filmes de purê de frutas e hortaliças, diferentes aditivos têm sido avaliados com o objetivo de melhorar essas características. Pectina, metilcelulose, hidoxipropilmetilcelulose, gelatina, amido de milho são exemplos de alguns estabilizantes naturais que já foram estudados e adicionados com o objetivo de elevar a resistência e propriedades de barreira. Mais recentemente, produtos gerados por nanotecnologia têm sido aplicados em filmes biodegradáveis com resultados promissores. Na Embrapa tem sido estudada a incorporação de nanopartículas (orgânicas e inorgânicas) e de nanofibras, de diversas origens, como elementos reforçadores da matriz polimérica. Nanoelementos, por suas dimensões reduzidas e por serem altamente reativos, estabelecem fortes interações com as estruturas celulósicas internas do filme. A incorporação de nanopartículas orgânicas, como as processadas tendo por base polissacarídeos (quitosana, por exemplo), tem se mostrado eficiente na consolidação da microestrutura e nanofibras de celulose mostraram-se ser altamente eficientes na redução da permeação ao vapor de água.

O uso de produtos oriundos da nanotecnologia na área de embalagens e principalmente em alimentos é uma tendência irreversível (DUNCAN, 2011; ALMEIDA et al., 2015) e tem sido avaliado principalmente no processamento de plásticos com caráter ativo (antimicrobianos, antioxidantes, etc) e para o controle das características mecânicas e principalmente no aumento do efeito de barreira (redução da permeação de vapores, solutos ou aromas).

\section{ASPECTOS NORMATIVOS}

Os plásticos obtidos a partir de polpas de frutas têm sido frequentemente considerados como "filmes comestíveis" por tratarem-se do processamento realizado a partir de matéria prima comestível e de fonte natural (AZEREDO et al., 2012), embora de acordo com a legislação brasileira não haja uma normatização específica para este tipo de produto. Normalmente polpas e purês processados a partir de frutas e hortaliças têm sido internacionalmente reconhecidas como GRAS (Generally Recognized as Safe), ou seja, são em princípio atóxicas e seguras para o uso em ou como alimento, desde que não haja a adição de conservantes sintéticos. No Brasil, os materiais empregados para fins de embalagens que 
entram em contato com alimentos devem seguir uma normatização, de acordo com as exigências da ANVISA (Agência Nacional de Vigilância Sanitária) e estarem classificados dentro de sua "Lista Positiva de Polímeros e Resinas". No caso dos filmes elaborados com polpas, após a sequência de processamento estes, para se adequarem dentro das exigências preconizadas pela ANVISA, não podem gerar a migração de componentes indesejáveis para os alimentos, em condições que superem os limites estabelecidos pela Resolução RDC no 91 (ANVISA, 2001). Esta resolução também estabelece que o material plástico não ocasione alterações nas características sensoriais dos alimentos, ou seja, embora atributos como cor, sabores e aromas possam ser preservados ou agregados nos filmes à base de polpas, estes não podem interferir nas características originais dos produtos que estão sendo protegidos ou transportados. Assim, torna-se importante análises detalhadas do processamento e da elaboração de formulações, principalmente na escolha e incorporação de aditivos e nanoestruturas que sejam estáveis e fortemente ligados à matriz celulósica.

Para o Mercosul, embalagens processadas a base de fontes de composição celulósica têm na Portaria Normativa número 177/99 "Disposições Gerais Para Embalagens e Equipamentos Celulósicos em Contato com Alimentos" as diretrizes a serem seguidas (ANVISA, 1999). Deve-se também atentar à adição de estruturas de reforço em escala manométricas, considerando que não existe ainda uma legislação específica para o uso de nanotecnologia na área de embalagens para alimentos em vigor no Brasil (ALMEIDA et al., 2015).

\section{CONSIDERAÇÕES FINAIS}

Com respeito ao exemplo de processamento apresentado, cabe salientar que o Brasil é o maior produtor mundial de mamão, com uma produção estimada em 1.898 .000 toneladas por ano (EMBRAPA, 2009), ou aproximadamente $30 \%$ da produção mundial. As perdas nacionais de mamão somam em média $30 \%$ do total produzido (BENATO, 1999), o que representa em torno de 570.000 toneladas de resíduos descartados anualmente.

Pelo processo descrito e correntemente em aperfeiçoamento junto a Embrapa, tem-se o aproveitamento próximo a 50\% desse rejeito na produção de polpa. Sementes, caroços ou cascas com características fibrosas são descartadas por apresentarem baixa solubilidade. Essa relação de aproveitamento é interessante ao considerarmos o custo da matéria prima que pode ser considerado praticamente nulo e de grande disponibilidade.

Empresas processadoras de plásticos convencionais apresentam, em princípio, toda a infraestrutura necessária para a produção de filmes de polpa de frutas. Além de benefícios ambientais, a produção de polímeros biodegradáveis agrega valor à imagem de sustentabilidade das empresas. Melhorias nas propriedades gerais dos filmes e adequação às normas atualmente vigentes podem ser conseguidas pela mistura ou formação de blendas com demais biopolimeros ou mesmo com pequenas adições de materiais sintéticos sem as perdas das características de biodegradabilidade originais. De um modo geral o processo é atrativo e a viabilidade do ponto de vista econômico deve ser avaliada pelos setores produtivos. 
Os autores são gratos à FAPESP, CNPq e a Rede AgroNano (Embrapa)/LNNA (Laboratório Nacional de Nanotecnologia para o Agronegócio), por recursos disponibilizados.

\title{
Use of horticultural chain rejects in the processing of biodegradable plastics
}

\begin{abstract}
The basic process of producing biodegradable plastics, of interest to the packaging industry, by using rejects or discards of the horticultural chain as raw material is presented and commented. The main aim here is to draw the interest of the industrial polymer sector in performing studies of economic feasibility of the proposed process. Brazil is one of the largest producer of fruits and vegetables, although is also considered a country that has one of the biggest losses in this segment. Over-ripe fruits, inappropriate for consumption or wastes from the agro-industrial processing are ordinary underutilized or even discharged as waste in nature. If properly processed, they can constitute in a raw material of interest for the production of biodegradable plastic films, mainly for food packaging purpose. The losses or residues add up around $40 \%$ of all fruit production, which means a large source of removable raw material at low cost that can be used by the synthetic plastic industry, not only to increase the product portfolio, but also to add value to the image of sustainability. The processing of films from papaya pulp is presented as a practical illustrative example.
\end{abstract}

KEYWORDS: Packaging. Biodegradable Plastics. Agro-industrial Wastes. Sustainable Processing. 


\section{REFERÊNCIAS}

ABIPLAST - Associação Brasileira da Indústria de Plástico. A Indústria Brasileira de Transformação de Material Plástico. Perfil ABLIPLAST 2014, p. 37, 2014.

ALMEIDA, A.C.S.; FRANCO, E.A.N.; PEIXOTO, F.M., PESSANHA, K.L.F.; MELO, N.R. Aplicação de nanotecnologia em embalagens de alimentos. Polímeros - Ciência e Tecnologia, v. 25, p. 89-97, 2015.

ANVISA - Agência Nacional de Vigilância Sanitária. Regulamento Técnico Disposições Gerais Para Embalagens e Equipamentos Celulósicos em Contato com Alimentos e seus Anexos. Portaria n. 177, de 04 de março de 1999. GACTA/GGALI/ANVISA, Brasília, DF, 1999.

ANVISA - Agência Nacional de Vigilância Sanitária. Regulamento Técnico Critérios Gerais e Classificação de Materiais para Embalagens e Equipamentos em Contato com Alimentos. Resolução RDC n. 91, de 11 de maio de 2001. GACTA/GGALI/ANVISA Brasília, DF, 2001.

AZEREDO, H.M.C; MATTOSO, L.H.; WOOD, D.; WILLIAMS, T.G.; AVENA-BUSTILLOS, R.J.; McHUGH, T.H. Nanocomposite edible films from mango puree reinforced with cellulose nanofibers. Journal of Food Science, v. 74, n. 5, p. N31-N35, 2009. crossref

AZEREDO, H.M.C.; MIRANDA, K.W.E.; ROSA, M.F.; NASCIMENTO, D.M.; DE MOURA, M.R. Edible films from alginate-acerola puree reinforced with cellulose whiskers. Lebensmittel Wissenschaft - Technologie / Food Science Technology, v. 46, n. 1, p. 294-297, 2012.

BENATO, E.A. Controle de doenças pós-colheita em frutos tropicais. Summa Phytopathologica, v. 25, n. 1, p. 90-93, 1999.

BRAZILIAN FRUIT. Disponível em: < http://www.brazilianfruit.org.br/newbrazilianfruit.asp> Acesso em: 14 nov. 2016.

CRUZ S. S.; MORAIS A. B. F.; RIBEIRO S. B.; DE OLIVEIRA M. G.; DA COSTA M. S.; FEITOSA C. T. L. Resíduo de frutas na alimentação de ruminantes. Revista Eletrônica Nutritime, v. 10, n. 06, p. 2909-2931, 2013.

DCl, Diário do Comércio Indústria \& Serviços, Sessão Opinião, Cadeia do Plástico. S. Paulo, SP. Edição de 26 de junho de 2016, p. 2, 2016. 
DE BARROS, Taís Téo. Produção e caracterização de filmes de polpa de mamão com adições de nanoestruturas, processados em modo batelada. Dissertação de Mestrado (Mestrado em Biotecnologia), Universidade Federal de São Carlos, 2016.

DITCHFIELD, C.; TADINI, C.C. Produção de purê de banana de alta qualidade a partir de frutas rejeitadas para comercialização. In: Produção de Alimentos: busca de soluções para a fome. Organização Grupo Gerdau. CNPq, Eletrobrás e Fundação Roberto Marinho, Porto Alegre, RS. p. 47-86, 2005.

DU, W.X.; OLSEN, C.W.; AVENA BUSTILLOS, R.J.; McHUGH, T.H.; LEVIN. C.E.; FRIEDMAN, M. Antibacterial activity against E-coli 0157: H7, physical properties, and storage stability of novel carvacrol containing edible tomato films. Journal of Food Science, v. 73, n. 7, p. M378-83, 2008. crossref

DUNCAN, T.V. Applications of nanotechnology in food packaging and food safety: Barrier materials, antimicrobials and sensors. Journal of Colloid and Interface Science, v. 363, n. 1, p. 1-24, 2011. crossref

EHRENBRING, H.Z.; TUTIKIAN, B.F. Concretos reforçados com fibras naturais e fibras recicladas. In: Anais do $7^{\circ}$ Fórum Internacional de Resíduos Sólidos: Resíduos Sólidos e Mudanças Climáticas. Porto Alegre, RS, 15 a 17 de junho de 2016. Instituto Venturini, RS, 11p., 2016.

EMBANEWS - Resistir é preciso. Revista EmbaNews, p. 28-32, edição de dezembro de 2016.

EMBRAPA - Empresa Brasileira de Pesquisa Agropecuária. Coleção Plantar: Mamão. 3ạ. Edição revisada e ampliada. Embrapa Informação Tecnológica, Brasília, DF. 119p. 2009.

FARIAS, M.G.; FAKHOURI, F.M.; CARVALHO, C.W.P.; ASCHERI, J.L.R. Caracterização físico-química de filmes comestíveis de amido adicionado de acerola (Malphigia emarginata DC). Química Nova, v. 35, n. 3, p. 546-552, 2012. crossref

IBGE - Instituto Brasileiro de Geografia e Estatística. Disponível em: <http://www.ibge.gov.br/home/estatistica/pesquisas/indicadores.php>. Acesso em 16 nov. 2016.

LOREVICE, M. V.; MOURA, M. R.; AOUADA, F.A. ; MATTOSO, L. H. C. Development of novel guava puree films containing chitosan nanoparticles. Journal of Nanoscience and Nanotechnology, v. 12, n. 3, p. 2711-2717, 2012. crossref 
LOREVICE, M. V.; MOURA, M. R.; MATTOSO, L. H. C. Nanocomposite of papaya puree and chitosan nanoparticles for application in packaging. Química Nova, v. 37 , n. 6, p. 931-936, 2014. crossref

MARTELLI, M.R., BARROS, T.T; MOURA, M.R.; MATTOSO, L.H.; ASSIS, O.B.G. Effect of chitosan nanoparticles and pectin content on mechanical properties and water vapor permeability of banana puree films. Journal of Food Science, v. 78, n. 1, p. N98-N104, 2013. crossref

MARTELLI, M.R.; BARROS, T.T.; ASSIS, O.B.G. Produção de filmes plásticos a partir de polpa de frutas sobremaduras. Revista Brasileira de Produtos Agroindustriais, v. 17, n. 3, p. 301-308, 2015. crossref

MARTELLI-TOSI, M.; ASSIS, O.B.G.; SILVA, N.C.; ESPOSTO, B.S.; MARTINS, M.A.; TAPIA-BLÁCIDO, D.R. Chemical treatment and characterization of soybean straw and soybean protein isolate/straw composite films. Carbohydrate Polymers, v. 157, n. 1 , p. 512-520, 2017. cross ref

McHUGH, T.H.; HUXSOLL, C.C.; KROCHTA, J.M. Permeability properties of fruit puree edible films. Journal of Food Science, v. 61, n. 1, p. 88-91, 1996. crossref

MORETTI, C.L. Aproveitamento de resíduos do processamento mínimo de frutas e hortaliças. In: IV Encontro Nacional de Processamento Mínimo, São Pedro, SP, Brasil, de 04 a 07 de abril de 2006. Disponível em:

<http://www.esalq.usp.br/departamentos/Ipv/eventos/palestras/IV\%20EMP\%20 Moretti.pdf>. Acesso em: 14 nov. 2016.

NASCIMENTO-FILHO W. B.; FRANCO C. R. Avaliação do potencial dos resíduos produzidos através do processamento agroindustrial no Brasil. Revista Virtual de Química. v. 7, n. 6 p. 1968-1987, 2015.

ROJAS GRAÜ, M.A.; AVENAS BUSTILLOS; OLSEN, C.; FRIEDMAN, M.; HENIKA, P.R.; MARTIN BELLOSO, O.; PAN, Z.; McHUGH, T.H. Effects of plant essential oils and oil compounds on mechanical, barrier and antimicrobial properties of alginate-apple puree edible films. Journal of Food Engineering, v. 81, n. 3, p. 634-641, 2007.

crossref

ROSA, M. F.; SOUZA FILHO, M. S. M.; FIGUEIREDO, M. C. B.; MORAIS, J. P. S.; SANTAELLA, S.T., LEITÃO, R.C. Valorização de resíduos da agroindústria. In: ॥ Simpósio Internacional sobre Gerenciamento de Resíduos Agropecuários e Agroindustriais (SIGERA), Foz do Iguaçu, PR, Brasil, 15 a 17 de março de 2011. In: Anais do II SIGERA, vol.1, p.98-105, 2011. 
SABIO, R.P.; PAGLIUCA, L.G.; JULIÃO, L. DELEO, J.P.B.; BOTEON, M. Anuário Hortifruti Brasil Retrospectiva 2015 \& Perspectiva 2016. Hortifruti Brasil, vol. Dez/Jan., p. 12-16, 2016.

SANTANA-MÉRIDAS, O.; GONZÁLEZ-COLOMA, A.; SÁNCHEZ-VIOQUE, R. Agricultural residues as a source of bioactive natural products. Phytochemistry Reviews, v. 11, n. 4, p. 447-466, 2012. crossref

SANTOS, K.; VIEIRA, W. Destino final: o lixo. Comunicado especial: Abastecer Brasil. Associação Brasileira das Centrais de Abastecimento, n. 5, p. 8-12, 2011.

SEAB - Secretaria de Estado da Agricultura e do Abastecimento. Fruticultura Análise de conjuntura Agropecuária. Boletim do DERAL - Departamento de Economia Rural. 11p, 2011. Disponível em: < http://www.agricultura.pr.gov.br/arquivos/File/deral/Prognosticos/fruticultura_2 012_13.pdf>. Acesso em 06 fev. 2017.

SILVA, E.R. Biodegradação fungica de residuos agroindustriais para a produção de biomassa microbiana, enzimas ligninoceluloliticas e redução de fitatos. Campinas, Tese de Doutorado em Ciência dos Alimentos. Unicamp, 2001.

SILVEIRA, E. Embalagens verdes. Pesquisa FAPESP, n. 242, edição de abril, pp. 7375, 2016.

SOUZA O.; SCHULZ M. A.; FISCHER G. A. A.; WAGNER T. M.; SELLIN N. Energia alternativa de biomassa: Bioetanol a partir da casca e da polpa de banana. Revista Brasileira de Engenharia Agrícola e Ambiental. v. 16, n. 8, p. 915-921, 2012. crossref

WANG, X.; SUN, X.; LIU, H.; LI, M.; MA, Z. Barrier and mechanical properties of carrot puree films. Food and Bioproducts Processing, v. 89, n. 2, p. 149-156, 2011. crossref 
Recebido: 30 nov. 2017

Aprovado: 22 out. 2017

DOI: 10.3895/gi.v13n2.5089

Como citar:

BARROS, T. T.; TOSI, M. M.; ASSIS, O. B. G. Aproveitamento de rejeitos da cadeia hortofrutícula no processamento de plásticos biodegradáveis. R. Gest. Industr., Ponta Grossa, v. 13, n. 2, p. 215-229, jun./ago. 2017. Disponível em: <https://periodicos.utfpr.edu.br/rgi>. Acesso em: XXX

Correspondência:

Odílio Benedito Garrido Assis

Rua XV de Novembro, 1452, caixa postal 741, São Carlos, São Paulo, Brasil.

Direito autoral: Este artigo está licenciado sob os termos da Licença Creative Commons-Atribuição 4.0

Internacional.

(c) (i) 